\title{
Effect of low to moderate levels of smoking and alcohol consumption on serum immunoglobulin concentrations
}

\author{
S A McMillan, J P Douglas, G P R Archbold, E E McCrum, A E Evans
}

\begin{abstract}
Aim-To determine the effect of low to moderate levels of smoking and alcohol consumption on immunoglobulin concentrations.

Methods-Serum samples from 1787 subjects with approximately equal numbers in each five year group from 15 to 64 years were obtained from a large random population survey in Northern Ireland. Details were available on each subject concerning the number of units of alcohol consumed per week and the number of cigarettes smoked per day. IgG, IgM, and IgA concentrations were measured by laser nephelometry on all serum samples.

Results-Low to moderate consumption of alcohol was associated with a decrease in IgG and IgM median concentrations in contrast to an increase in IgA median concentrations. The decrease in IgM and especially IgG median concentrations appeared to be related to the smoking habits of the subjects. Alcohol consumption alone was associated with increased IgA median concentrations whereas cigarette smoking alone was associated with reduced IgG median concentrations.

Conclusion-Low levels of alcohol consumption and cigarette smoking influence IgG, IgM, and IgA serum concentrations. This should be borne in mind when selecting subjects for use in research and clinical settings.

$(\mathcal{F}$ Clin Pathol 1997;50:819-822)
\end{abstract}

Keywords: immunoglobulins; alcohol consumption; smoking; reference intervals

cal Chemistr

Department, Belfast

City Hospital Trust,

Belfast, UK

G P R Archbold

Department of

Epidemiology and

Public Health, The

Queens University of

Belfast, Belfast, UK

E E McCrum

A E Evans

Correspondence to: Dr McMillan, Regional Immunology Service,

Microbiology Building, Royal Group of Hospitals, Belfast BT12 6BN, UK

Accepted for publication 12 June 1997 biological variation within the population or analytical interferences of the analyte being measured. These include health associated risk factors, different physiological states, and the intake of pharmacologically active agents such as drugs, alcohol, and tobacco. ${ }^{3}$

Cigarette smoking and alcohol consumption are common among the healthy population, and both have been associated with changes in immune status. Cigarette smoking has been shown to affect $\mathrm{T}$ cell subsets, natural killer cells, and serum immunoglobulin concentrations. ${ }^{46}$ Alcohol consumption, especially heavy consumption, is associated with changes in lymphocyte populations and increased serum immunoglobulin concentrations. ${ }^{7}$ However, little is known of the effect on immunoglobulin concentrations of low to moderate consumption of alcohol and the smoking of low to moderate numbers of cigarettes, or how these two factors interact. Here, we report the effects of low to moderate levels of smoking and consumption of alcohol on immunoglobulin concentrations in a well defined large population study. The results may help to explain the differences in immunoglobulin concentrations and references ranges obtained from different studies.

\section{Methods}

SUBJECTS

In Northern Ireland the Belfast MONICA (Multinational monitoring of trends and determinants in cardiovascular disease) project and the Change of heart survey were set up between 1983 and 1992 to determine the risk factors associated with coronary heart disease in the population. ${ }^{9}$ These populations were selected as single random samples by sex and age from patients on the Northern Ireland Central Service Agency's General Practitioners' list. Each subject consented to undergo an interview and was asked a series of general questions about their lifestyle. During the interview a blood sample was taken. Serum samples were available from two of the above surveys: Change of heart (1988) and MONICA 3 (1991-92). Subjects from the MONICA 3 survey were aged between 25 and 64 years and were from the Belfast area; subjects from the Change of heart survey were aged between 15 and 64 years and were from the rest of Northern Ireland outside the Belfast area.

Our study investigated 1787 samples from both these surveys with approximately equal numbers of males and females (876 and 911, respectively) and approximately equal numbers in each five year group between 15 and 64 years. 
Table 1 Effect of number of units of alcohol consumed per week on the median concentrations and reference intervals for immunoglobulins in all subjects

\begin{tabular}{|c|c|c|c|c|c|c|}
\hline & \multicolumn{4}{|c|}{ Units of alcohol consumed per week } & \multirow[b]{2}{*}{$p$ value* } \\
\hline & & $\begin{array}{l}0 \\
(n=792)\end{array}$ & $\begin{array}{l}1-20 \\
(n=670)\end{array}$ & $\begin{array}{l}21-40 \\
(n=187)\end{array}$ & $\begin{array}{l}>40 \\
(n=138)\end{array}$ & \\
\hline IgG & $\begin{array}{l}\text { Median } \\
\text { Reference interval }\end{array}$ & $\begin{array}{l}11.50 \\
7.6-17.3\end{array}$ & $\begin{array}{l}11.40 \\
7.4-16.8\end{array}$ & $\begin{array}{l}11.20 \\
7.2-16.3\end{array}$ & $\begin{array}{l}10.95 \\
7.2-15.8\end{array}$ & 0.002 \\
\hline $\operatorname{IgM}$ & $\begin{array}{l}\text { Median } \\
\text { Reference interval }\end{array}$ & $\begin{array}{l}1.35 \\
0.5-3.6\end{array}$ & $\begin{array}{l}1.33 \\
0.5-3.2\end{array}$ & $\begin{array}{l}1.20 \\
0.4-2.9\end{array}$ & $\begin{array}{l}1.17 \\
0.4-2.8\end{array}$ & 0.002 \\
\hline IgA & $\begin{array}{l}\text { Median } \\
\text { Reference interval }\end{array}$ & $\begin{array}{l}2.10 \\
0.7-4.8\end{array}$ & $\begin{array}{l}2.22 \\
0.9-4.8\end{array}$ & $\begin{array}{l}2.34 \\
1.0-5.3\end{array}$ & $\begin{array}{l}2.35 \\
0.4-5.4\end{array}$ & 0.0001 \\
\hline
\end{tabular}

Values are in $\mathrm{g} / \mathrm{l}$.

^Kruskal-Wallis one way ANOVA.

ALCOHOL CONSUMPTION AND SMOKING

As part of the survey, subjects were interviewed and questioned about their life style including the number of units of alcohol consumed per week and the number of cigarettes smoked per day. A unit of alcohol was $8 \mathrm{~g}$ of ethanol and for this study was equated to a glass of wine or a bottle/half pint of beer. ${ }^{10} \mathrm{~A}$ measure of spirits in Northern Ireland is equal to -1.5 units. To ensure sufficient numbers of subjects for statistical analysis, alcohol consumption was categorised into the following groups: no alcohol consumed, 1-20 units of alcohol consumed per week, 21-40 units consumed per week, and $>40$ units consumed per week. (In the last group a total of 40 subjects consumed more than 80 units of alcohol per week.) Cigarette smoking was also categorised into groups: no cigarettes smoked, 1-10 cigarettes smoked per day, 11-20 cigarettes smoked per day, and $>20$ cigarettes smoked per day. (In the last group only seven subjects smoked more than 40 cigarettes per day.) Subjects who did not smoke were grouped according to their alcohol consumption and subjects who did not consume alcohol who were grouped according to the number of cigarettes smoked. Information was also available on the number of subjects in the non-smoking group that had never smoked, had occasionally smoked, or had regularly smoked in the past.

\section{IMMUNOGLOBULIN CONCENTRATIONS}

Serum concentrations of IgG, IgM, and IgA were measured by laser nephelometry using a Beckman Array Protein system (Beckman Instruments, High Wycombe, Bucks, UK) with appropriate Beckman standards and controls. The analytical coefficient of variation of the method is below $3 \%$. Standardisation was to the IFCC international reference preparation for plasma proteins (Lot CRM 470).

DATA STORAGE AND STATISTICAL ANALYSIS

Data storage and statistical analysis were performed using SPSS for Windows release 6.0 software. Information stored on each patient included survey identification number, age, sex, amount of alcohol consumed in units per week, number of cigarettes smoked per day, and concentrations of IgG, IgM, and IgA. Statistical analyses included the calculation of medians, maximum and minimum values, $2.5 \%$ and $97.5 \%$ percentiles. Kruskal-Wallis one way analysis of variance was used for overall comparisons within groups and the Mann-
Whitney U test, with the Bonferroni correction for multiple comparisons, was used to compare individual subgroups within each group.

ESTABLISHMENT OF REFERENCE INTERVALS

The reference intervals were calculated for IgG, IgM, and IgA as the central $95 \%$ of results bounded by the $2.5 \%$ and $97.5 \%$ percentiles. $^{3}$ As the distribution of all three immunoglobulins in the study population differed from a gaussian distribution, the non-parametric method based on rank numbers was used to define the central $95 \%$ reference values bounded by the $2.5 \%$ and $97.5 \%$ percentiles. Reference values by sex and age groups (15-30, 31-45, and 46-65 years) were also calculated.

In the calculation of the reference values of all three immunoglobulin classes extreme values were excluded if the difference between the extreme value and the next value was greater than one third of the entire range. ${ }^{11}$

\section{Results}

SMOKING AND ALCOHOL CONSUMPTION IN THE STUDY GROUP

In the study group, $29 \%$ (521) subjects smoked one or more cigarettes per day and 56\% (995) consumed at least one unit of alcohol per day. Eight per cent (147) smoked but did not drink alcohol, and 35\% (619) consumed alcohol but did not smoke. Twenty one per cent (374) both consumed alcohol and smoked whereas 36\% (647) neither consumed alcohol nor smoked. Of the 1266 subjects who said that they were non-smokers, 778 (62\%) had never smoked, $97(8 \%)$ had occasionally smoked in the past, and $381(30 \%)$ had smoked regularly in the past.

\section{IMMUNOGLOBULIN CONCENTRATIONS AND}

ALCOHOL INTAKE

There was a significant decrease in both median concentrations of $\mathrm{IgG}$ and $\mathrm{IgM}$ isotypes in the study population with increasing alcohol consumption (IgG, $p=0.002 ; \operatorname{Ig} M$, $p=0.002)$. This decrease was also seen in the different reference intervals calculated for each group (table 1). The median IgG value decreased by $5 \%$ from the no alcohol value to the value for subjects consuming greater than 40 units per week. The median IgM concentration decreased by $13 \%$ from the no alcohol value to the value for subjects consuming over 40 units per week. In contrast, IgA concentrations showed a significant increase with alcohol consumption ( $p=0.0001$ ), with subjects who consumed greater than 40 units per week showing an increase of $12 \%$ over the no alcohol group. Again, this was reflected in the different reference intervals calculated (table 1).

Immunoglobulin concentrations were also determined in subjects who did not smoke but consumed alcohol, showing that low to moderate alcohol consumption had no significant effect on IgG and IgM median values (IgG, $\mathrm{p}=0.4 ; \operatorname{IgM}, \mathrm{p}=0.2$ ) (table 2). However, in non-smokers the IgA median values again increased significantly with alcohol consumption, showing an increase of $22 \%$ in subjects 
Table 2 Effect of number of units of alcohol consumed per week on the median concentrations and reference intervals for immunoglobulins in non-smokers

\begin{tabular}{llllll}
\hline \multicolumn{5}{c}{ Units of alcohol consumed per week } & \\
\cline { 3 - 5 } & & 0 & $1-20$ & $>20$ \\
$(n=647)$ & $(n=466)$ & $(n=153)$ & p value \\
\hline IgG & Median & 11.7 & 11.5 & 11.6 & 0.4 \\
& Reference interval & $7.6-17.4$ & $7.6-16.5$ & $7.6-17.2$ & \multirow{2}{*}{ IgM } \\
\cline { 3 - 5 } IgA & Median & 1.35 & 1.36 & 1.35 & 0.2 \\
& Reference interval & $0.5-3.7$ & $0.5-3.2$ & $0.5-2.8$ & \multirow{2}{*}{0.0001} \\
& Median & 2.10 & 2.28 & 2.57 & \\
\hline
\end{tabular}

Values are $\mathrm{g} / \mathrm{l}$

^Kruskal-Wallis one way ANOVA

Table 3 Effect of number of cigarettes smoked per day on the median concentrations and reference intervals for immunoglobulins in all subjects

\begin{tabular}{|c|c|c|c|c|c|c|}
\hline & & \multicolumn{4}{|c|}{ Number of cigarettes smoked per day } & \multirow[b]{2}{*}{$p$ value } \\
\hline & & $\begin{array}{l}0 \\
(n=1266)\end{array}$ & $\begin{array}{l}1-10 \\
(n=181)\end{array}$ & $\begin{array}{l}11-20 \\
(n=240)\end{array}$ & $\begin{array}{l}>20 \\
(n=100)\end{array}$ & \\
\hline \multirow[t]{2}{*}{ IgG } & Median & 11.60 & 10.80 & 10.40 & 9.60 & 0.0001 \\
\hline & Reference interval & $7.6-17.0$ & $7.6-15.8$ & $6.9-15.2$ & $6.3-14.5$ & \\
\hline \multirow[t]{2}{*}{ IgM } & Median & 1.33 & 1.30 & 1.28 & 1.24 & 0.04 \\
\hline & Reference interval & $0.5-3.4$ & $0.5-3.0$ & $0.5-2.9$ & $0.4-3.2$ & \\
\hline \multirow[t]{2}{*}{$\operatorname{Ig} A$} & Median & 2.22 & 2.16 & 2.10 & 2.10 & 0.07 \\
\hline & Reference interval & $0.8-5.0$ & $0.7-4.9$ & $0.7-4.3$ & $1.1-5.4$ & \\
\hline
\end{tabular}

Values are $\mathrm{g} / \mathrm{l}$.

^Kruskal-Wallis one way ANOVA.

Table 4 Effect of number of cigarettes smoked per day on the median concentrations and reference intervals for immunoglobulins in subjects who did not consume alcohol

\begin{tabular}{llllll}
\hline \multicolumn{5}{c}{ Number of cigarettes smoked per day } & \\
\cline { 3 - 5 } & & 0 & $1-10$ & $>11$ & \\
& & $(n=647)$ & $(n=58)$ & $(n=87)$ & p value \\
\hline IgG & Median & 11.7 & 11.05 & 9.7 & 0.0001 \\
& Reference interval & $7.6-17.4$ & $7.8-15.8$ & $6.9-14.2$ & \\
IgM & Median & 1.35 & 1.34 & 1.31 & 0.86 \\
& Reference interval & $0.5-3.7$ & $0.4-3.1$ & $0.4-3.5$ & \multirow{2}{*}{ IgA } \\
\cline { 3 - 5 } & Median & 2.10 & 2.08 & 2.07 & 0.74 \\
& Reference interval & $0.7-4.8$ & $0.8-4.3$ & $0.6-5.1$ & \\
\hline
\end{tabular}

Values are $\mathrm{g} / \mathrm{l}$

^Kruskal-Wallis one way ANOVA.

Table 5 Median immunoglobulin concentrations according to age

\begin{tabular}{|c|c|c|c|c|c|}
\hline & All subjects & $\begin{array}{l}\text { No alcohol } \\
\text { consumed }\end{array}$ & $\begin{array}{l}\text { Alcohol } \\
\text { consumed }\end{array}$ & Non-smoker & Smoker \\
\hline \multicolumn{6}{|l|}{$\overline{I g G}$} \\
\hline $15-30$ years & 11.2 & 11.3 & 10.7 & 11.3 & 10.4 \\
\hline $31-45$ years & 11.2 & 11.3 & 10.9 & 11.8 & 10.5 \\
\hline $46-65$ years & 11.5 & 11.8 & 11.2 & 11.7 & 10.8 \\
\hline \multicolumn{6}{|l|}{$\operatorname{Ig} M$} \\
\hline $15-30$ years & 1.32 & 1.36 & 1.31 & 1.40 & 1.30 \\
\hline $31-45$ years & 1.34 & 1.38 & 1.30 & 1.41 & 1.31 \\
\hline $46-65$ years & 1.33 & 1.35 & 1.31 & 1.35 & 1.25 \\
\hline \multicolumn{6}{|l|}{$\operatorname{Ig} A$} \\
\hline $15-30$ years & 1.85 & 1.72 & 2.10 & 1.86 & 1.82 \\
\hline $31-45$ years & 2.20 & 2.11 & 2.24 & 2.32 & 1.95 \\
\hline $46-65$ years & 2.44 & 2.40 & 2.50 & 2.41 & 2.31 \\
\hline
\end{tabular}

Values are $\mathrm{g} / \mathrm{l}$

consuming greater than 20 units per week compared with subjects who did not consume alcohol (table 2).

\section{IMMUNOGLOBULIN CONCENTRATIONS AND}

CIGARETTE SMOKING

There was a statistically significant lowering of the median IgG serum concentration with increasing numbers of cigarettes smoked $(p=0.0001)$ as shown in table 3 . This difference was even observed between nonsmokers and subjects who smoked 10 or fewer cigarettes per day (Mann-Whitney, $\mathrm{p}=0.0004)$. Smoking more than 20 cigarettes per day was associated with a $17 \%$ lower IgG median concentration (table 3 ). Both IgM and IgA median concentrations also decreased with smoking; however, only the decrease in IgM concentrations was statistically significant. The effect of cigarette smoking on immunoglobulin concentrations was also determined in subjects who did not consume alcohol and only IgG concentrations were found to be significantly lower with smoking. Both IgM and IgA median concentrations did not change with increasing numbers of cigarettes smoked (table 4). Although the number of subjects who smoked but did not consume alcohol were small, there was a significant decrease in the median IgG concentration between subjects who did not smoke $(n=647)$ and those who did smoke ( $\mathrm{n}=145) \quad(\mathrm{IgG}, 11.7 \mathrm{mg} / \mathrm{l}$ and $10.23 \mathrm{mg} / \mathrm{l}$, respectively, $\mathrm{p}=0.001$ ) (table 4 ).

In the subjects who did not currently smoke, there was no significant difference in IgG, IgM, and IgA concentrations between those who had never smoked, had occasionally smoked in the past, or had regularly smoked in the past.

IMMUNOGLOBULIN CONCENTRATIONS AND THE AGE OF SUBJECTS WHO SMOKE AND CONSUME ALCOHOL

IgG and IgM concentrations showed no differences with increasing age. However, IgA concentrations showed a significant increase with increasing age $(p=0.023)$. Comparison of subjects in the age groups who did or did not smoke or consume alcohol reflected these concentrations (table 5). Similar values were seen between males and females with increasing age whether the subjects smoked or consumed alcohol (data not shown).

MEDIAN CONCENTRATIONS AND REFERENCE INTERVALS FOR IgG, IgM, AND IgA IN THE DIFFERENT GROUPS

Comparison of the median immunoglobulin concentrations in the groups of smokers, nonsmokers, drinkers, and non-drinkers showed a statistical decrease in IgG concentrations between subjects who did not smoke or drink and subjects who either smoked and did not drink or smoked and consumed alcohol (table 6). There was also a statistical decrease in IgM median concentrations between subjects who smoked or consumed alcohol and subjects who did not. These differences were reflected in the reference intervals for both IgG and $\operatorname{IgM}$, which were both considerably lower in subjects who smoked and consumed alcohol compared with those who did not. In contrast, median IgA concentrations were significantly increased in subjects who consumed alcohol, whether they smoked or not, compared with subjects who did not drink alcohol (table 6). The IgA reference interval did not appear to be affected by alcohol consumption or smoking.

\section{Discussion}

Our study has shown that the consumption of as few as 20 units of alcohol per week is associated with a significant increase in the median 
Table 6 Comparison of median concentrations and reference intervals of serum immunoglobulins

\begin{tabular}{lllll}
\hline & & $I g G$ & $I g M$ & $I g A$ \\
\hline All subjects (n=1787) & Median & 11.4 & 1.33 & 2.19 \\
& Reference interval & $7.4-16.5$ & $0.50-3.32$ & $0.85-4.90$ \\
Subjects who neither smoke & Median & $11.7^{\star} \dagger$ & $1.35 \ddagger$ & $2.10 \S$ \\
nor drink (n=647) & Reference interval & $7.6-17.4$ & $0.51-3.71$ & $0.71-4.82$ \\
Subjects who drink but do & Median & 11.6 & 1.32 & $2.339 ף$ \\
not smoke (n=619) & Reference interval & $7.6-16.7$ & $0.51-3.19$ & $0.98-5.14$ \\
Subjects who smoke but do & Median & $10.9^{\star}$ & 1.32 & 2.079 \\
not drink (n=147) & Reference interval & $7.1-16.8$ & $0.43-3.33$ & $0.65-4.77$ \\
Subjects who both smoke & Median & $10.5 \dagger$ & $1.24 \ddagger$ & 2.13 \\
and drink (n=374) & Reference interval & $6.9-15.3$ & $0.43-2.86$ & $0.87-4.79$ \\
\hline
\end{tabular}

Values are $\mathrm{g} / \mathrm{l}$.

Mann-Whitney $U$ test with Bonferroni correction: ${ }^{\star} p=0.0006 ; t p=0.0006 ; \neq p=0.0012$; $\Uparrow \mathrm{p}=0.0006 ; \uparrow \mathrm{p}=0.0003$ randomly selected males and females with equal numbers in the age range 15-65 years. Although this is a large population study, the small number of subjects in the group who did not consume alcohol but smoked may make the results pertaining to this particular group less robust. Ethnic differences are unlikely to contribute to the variation in immunoglobulin concentrations as the Northern Ireland population comprises a relatively stable homogeneous ethnic population. Most studies have reported alterations in immunoglobulin concentrations caused by drinking or smoking but these have been in highly selected groups such as blood donors, hospital patients, subjects taking part in drug trials, and captive groups (such as army volunteers) ${ }^{7}$ 12-15 and not in a randomly selected population.

In this study we have demonstrated that both smoking and alcohol consumption cause changes to immunoglobulin reference intervals; however, these ranges are still within clinically acceptable limits. The results emphasise the need to be aware of the factors that can influence concentrations of analytes when obtaining subjects for establishing reference intervals. Our study has confirmed that smoking and alcohol consumption are two such factors.

differences in immunoglobulin reference intervals calculated for the groups studied.

Serum IgA concentrations increased with age, but this did not appear to be a contributing factor to the increase in IgA concentrations with alcohol consumption as the age distribution within each alcohol group was approximately the same. It is interesting that subjects who do not smoke now but had smoked in the past had similar median immunoglobulin concentrations to those who had never smoked, suggesting that smoking has a direct but temporary effect on immunoglobulin concentrations.

There are now recommended criteria for establishing population based clinical reference intervals. ${ }^{1}$ These include the exclusion of individuals from the reference population due to biological variations. One such group are individuals taking pharmacologically active agents such as tobacco and alcohol. We have shown in our study that differences do occur in both immunoglobulin median concentrations and reference intervals when subjects are categorised according to whether they smoke cigarettes or consume alcohol. It appears that even low levels of smoking and drinking are associated with changes in immunoglobulin concentrations. This may partially explain the differences sometimes seen in immunoglobulin concentrations and reference intervals between different reported studies. In our random sample population $56 \%$ of individuals consumed alcohol and $29 \%$ of individuals smoked.

The strength of this study lies in its large sample size and its composition, the subjects were not from a defined group but were
1 National Committee for Clinical Laboratory Standards. How to define, determine, and utilize reference intervals in the clinical chemistry laboratory: proposed guideline. Villanova: NCCLS, 1991. (NCCLS Document C28-P.)

2 Sasse EA. Determination of reference intervals in the clinical laboratory using the proposed guideline National Committee for Clinical Laboratory Standards C28-P. Arch Pathol Lab Med 1992;116:710-13.

3 Solberg HE. Establishment and use of reference values. In: Burtis CA, Ashwood ER, eds. Fundamentals of clinical chemistry, 4th edn. Philadelphia: WB Sanders, 1996:18291.

4 Meliska CJ, Stunkard ME, Gilbert DG, Jensen RA, Martinko JM. Immune function in cigarette smokers who quit smoking for 31 days. $\mathcal{F}$ Allergy Clin Immunol 1995;95:901-10.

5 Gulsvik A, Fagerhol MK. Smoking and immunoglobulin levels. Lancet 1979;i:449.

6 Holt PG. Immune and inflammatory function in cigarette mokers. Thorax 1987;42:241-9.

7 Mili F, Flanders WD, Boring JR, Annest JL, DeStefano F. The association of alcohol drinking and drinking cessation to measures of the immune system in middle-aged men. Alcohol Clin Exp Res 1992;16:688-94. Immunoglobulin $\mathbf{A}$ in the diagnosis of alcoholic liver disease. Gastroenterology 1988;94:457-62.

9 Evans AE, McCrum EE, Patterson CC. The change of heart baseline clinical survey. $A$ report to the Health Promotion Agency. Belfast: The Queen's University of Belfast, 1990.

10 Royal College of Physicians, Royal College of Psychiatrists, Royal College of General Practitioners. Alcohol and the heart in perspective: sensible limits reaffirmed. London: RCP, RCPsych, RCGP, 1995.

11 Dixon WJ. Processing data for outliers. Biometrics 1953;9: 74-89.

12 Holt PG. Immune and inflammatory function in cigarette smokers. Thorax 1987;42:241-9. levels [letter]. Lancet 1979;i:449.

14 Andersen P, Pedersen OF, Bach B, Bonde GJ. Serum antibodies and immunoglobulins in smokers and nonsmokers. Clin Exp Immunol 1982;47:467-73.

15 Tollerud DJ, Morris Brown L, Blattner A, Weiss ST, Maloney EM, Kurman CC, et al Racial differences in cerum imm, serum ims smoning
8 van de Weil A, van Hattum J, Schuurman H-J, Kater L.

13 Gulsvik A, Fagerhol MK. Smoking and immunoglobulin 